\title{
Perceived Loudness of Neighbour Sounds Heard Through Heavy and Light-Weight Walls with Equal $R_{\mathrm{w}}+C_{50-5000}$
}

\author{
Monika Rychtáriková ${ }^{1,3)}$, Herbert Muellner²), Vojtech Chmelík ${ }^{3)}$, Nicolaas Bernardus Roozen ${ }^{1)}$, \\ Daniel Urbán ${ }^{3)}$, David Pelegrin Garcia ${ }^{1)}$, Christ Glorieux ${ }^{1)}$ \\ 1) KU Leuven, Soft Matter and Biophysics, Laboratory of Acoustics, Celestijnenlaan 200D, 3001 Heverlee, \\ Belgium \\ 2) Versuchsanstalt TGM, Fachbereich Akustik und Bauphysik, Wexstrasse 19-23, 1200 Wien \\ 3) STU Bratislava, Dep. of Building Constructions, Radlinského 11, 81108 Bratislava, Slovakia. \\ Monika.Rychtarikova@kuleuven.be
}

\begin{abstract}
Summary
This article presents a perceptual comparison of the loudness of a large range of 64 different typical "living room" sounds transmitted through two different walls: (1) a light-weight wall, composed of gypsum boards mounted on metal "C" studs and (2) a heavy-weight wall, built out of lime sand bricks plastered on one side. The two walls had different (laboratory measured) sound insulation spectra, but their Rw + C50-5000 rating was the same: $52 \mathrm{~dB}$. Compared to the heavy-weight wall, the massspring-mass-type light-weight wall had better sound insulation properties in the middle frequency range and worse at low frequencies below $100 \mathrm{~Hz}$ and above $3150 \mathrm{~Hz}$. Listening subjects had to choose the loudest stimuli between a pair of sounds (as transmitted through the lightweight and the masonry wall) presented through headphones in random order with one repetition, following a two-alternative forced choice (2AFC) procedure. Two sets of listening tests were conducted in this study, playing stimuli at realistic sound level and on artificially overall increased level. The listening experiments revealed significant differences in subjective assessment between the two types of acoustic insulation. The results also infer that the discussed single number rating does not adequately correspond with people's perception.
\end{abstract}

\section{Introduction}

For more than 5 decades and until today, the weighted airborne sound insulation single value ratings $R_{\mathrm{w}}$ and $D_{\mathrm{nT}}$,w of the sound insulation performance of building elements and buildings have been obtained according to the rating procedure described in ISO R 717: 1968 [1], ISO 717-1: 1982 [2], ISO 717-1: 1996 [3, 4], with the evaluation based on the frequency range from $100 \mathrm{~Hz}$ to $3150 \mathrm{~Hz}$. ISO 717-1:2013 [5] contains some improvements but is essentially the same as ISO 717-1:1996 + AM1:2006.

With each new generation, people's expectations on living comfort increase [6]. The evolution in inhabitants' desires on acoustical quality in domestic environments is not an exception to that trend. During the last few decades there has also been an evolution in the way of building: nowadays, more multi-storey buildings and multifamily houses are built in light-weight and timber construction modes. There are indications that, as a result of these evolutions, the currently applied requirements and descriptors are no longer adequately matching the residents' experience of the building acoustical comfort $[7,8]$. In response to this, efforts are ongoing to revise the rating procedures that will be applicable on future performance specifications of buildings (cf. e.g. [9, 10]) that take into account contemporary country and social related living aspects.

Already in the 1990s, discussions have emerged on the importance of including the octave band below the one of $100 \mathrm{~Hz}$ in the assessment of sound insulation $[6,7,8,11]$ and on including the frequency range at least down to $50 \mathrm{~Hz}$ in single number ratings to get more reliable correlations between these ratings and the residents' perceived sound insulation quality in dwellings. In the revised version of ISO 717: 1996 [3], so-called spectrum adaptation terms were introduced, as a result of which a wide range of new parameter combinations emerged. $R_{\mathrm{w}}+C_{50-3150,} R_{\mathrm{w}}+C_{50-5000,} D_{\mathrm{nT}, \mathrm{w}}+$

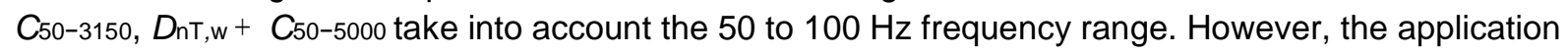
of the spectrum adaptation terms has been seen as too complex and is reluctantly used, if at all. 
During the past couple of years these currently applied descriptors have been revised and thoroughly discussed by different groups. The discussed revision of the method to characterise sound insulation properties of building elements and buildings is not only intended to lead to a simplification by minimizing the existing large number of single number quantities, but it has also been suggested to take the extended frequency range between $50 \mathrm{~Hz}$ and $100 \mathrm{~Hz}$ into account by default, rather than only as an option. Several researchers have therefore been working on the development of suitable measuring $[12,13,14]$ and prediction methods $[15,16,17,18]$, others have focused on the subjective assessment of sound insulation and on ways to perform listening tests [19, 20, 21, 22, 23, 24, 25, 26, 27].

Along with the activities mentioned above, there have been considerable efforts and initiatives in COST Action TU 0901 to find an approach to harmonize the application of the wide range of different descriptors currently applied in Europe $[10,28]$. Although the aim to establish new sound insulation descriptors has not yet been accomplished, it remains an open research subject whether the currently applied adaptation term spectra, which are taking the frequency range down to $50 \mathrm{~Hz}$ into account, really represent the given contemporary sound spectra [29] in multifamily houses of today. In order to define descriptors for further standardizations that correlate well with dwellers' perception of sound insulation quality and in order to make sure that none of the building modes are disadvantaged by single number ratings of sound insulation, it is necessary to investigate in detail the involved spectra and their impact on acoustic comfort and annoyance.

In the process of conceiving, verifying and selecting new objective acoustical parameters for sound insulation assessment, auralisation [20,30] and laboratory listening tests have become a very popular tool. In 1999 Mortensen [11] performed a study on perception of music sound with a frequency spectrum of road traffic noise. However, sounds in households were not addressed [15]. In 2009, Park and Bradley [19] compared standard airborne sound insulation measures on the basis of 20 different walls. However, the loudness of only 3 types of music and 3 types of speech stimuli was assessed, and the number of listening subjects (20) was rather limited, so that only trends in subjective perception could be indicated.

In 2012, Pedersen et al. [24] presented results on online listening tests for the assessment of sound insulation of walls using the ISO/TS 15666 annoyance scale [31]. Although the tested methodology for estimation of the annoyance potential (of airborne noise from neighbours) and the analysis of the results was thoroughly designed, a weak point of online assessment is a simple calibration procedure use in which a listener chooses his/her headphones with unknown frequency characteristics, and there is no information about the environment. The importance of playing the sound samples on correct levels is obvious, as the threshold, sensitivity and dynamic range of hearing is different for different frequencies. This issue is also discussed and verified in this paper. The influence of background noise on this matter was discussed by Horvat et al. [22]. Signal-to-noise margins in the laboratory were defined and the high importance of a noise-free environment for experiments on subjective sound insulation was demonstrated. Horvat et al. [23] also investigated the suitability of 3D sound reproduction, such as common spatial audio reproduction techniques, for listening tests, as some authors show concern on the reproduction of low frequencies in headphone experiments. It was shown that the use of open headphones with flat spectral characteristics can help to avoid many background noise issues.

In 2013, Ordoñez et al. [26] investigated façade insulation of 10 different construction types in typical Italian buildings (in accordance with the ISO 140-5 standard). Three psychoacoustic methods were compared and it was also suggested that in order to obtain reliable results a wider variety of stimuli is necessary. Recent studies on single number ratings were performed by Hongisto et al. [21] and Bailhache et al. [27]. In the study of Hongisto et al., correlations of twelve standardized single-number quantities with subjective perception were investigated. Six living sound types (two music sounds, speech, guitar, baby cry and dog bark) were presented as transmitted through nine walls with different frequency characteristics to 59 listening subjects. Moreover, Hongisto et al. concluded that the $50-80 \mathrm{~Hz}$ sound reduction index can be omitted in the single-number quantities.

An interesting field study can be found in [32] where it is concluded that when the airborne sound insulation is close to $R^{\prime}{ }^{\prime}=55 \mathrm{~dB}$, there is no statistically significant difference between the acoustic situation experienced with light-weight and heavy-weight walls in acoustic satisfaction. The results also 
suggest that $R^{\prime}$ w corresponds with subjective assessment better than $R_{w}+C_{50-5000}$. However, to confirm this on a more general level, larger studies need to be performed. It would also be interesting to compare results between different countries, since perception of annoyance can be influenced by a person's background. Behaviour of users might play a very dominant role in field studies and because of this, laboratory tests give more objective results when only loudness perception (and thus not the annoyance issues) are addressed.

It should be remarked that, although substantial amount of research has been done on the investigation of equal loudness contours [33] based on pure tone experiments (for an overview see [34]), and on the loudness perception of stationary sounds [35, 36], less is known about the loudness perception of sounds with rich temporal structure and loudness perception and disturbance of sounds that carry information and content [37, 38, 39]. None of the recent studies have explicitly focused on the question whether the spectrum (e.g. pink noise) and the frequency weighting (A-weighting)

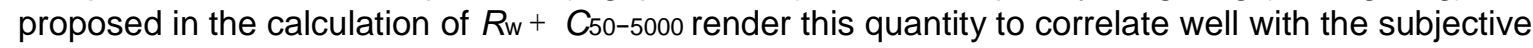
perception of the most prominent daily life sounds.

In this study we report on results obtained by presenting 64 different sound stimuli with a large variety of spectra, filtered through 2 very different walls to 39 subjects. We also highlight the cumbersome effect of playing sound stimuli on non-realistic absolute sound levels, which occurs when researchers perform studies in "silent" but not "noise-free" environments. For the sake of feasibility in terms of not making the listening tests too long, we have aimed only at the most discussed parameter $R_{w}+$ C50-5000.

The main addressed research questions can be formulated as follows:

1. Does broadband noise with a "pink" spectrum adequately describe neighbours' noise in dwellings and do "living noise" stimuli sound equally loud when transmitted through a light-weight and a heavy-weight wall (with the same $\left.R_{w}+C_{50}-5000\right)$ ?

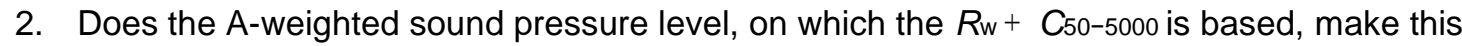
quantity correspond well with the perceived loudness of neighbours' noise?

The latter question refers to the simple calculation of the A-weighted sound pressure level and Loudness (son) of the reference signal prescribed by the standard so called "pink noise" filtered through the light-weight and the heavy-weight walls. For example, in the case of a source signal of 80 $\mathrm{dB}$ pink noise, the received A-weighted sound pressure level is the same $(40 \mathrm{~dB})$ when filtered through each wall (having the same $R_{w}+C_{50}-5000$ of $40 \mathrm{~dB}$ ). However, the Loudness indicates that the sounds transmitted through the heavy-weight wall ( 3 son) should sound louder in comparison with the lightweight wall (2 son). It should also be remarked that pink noise is only a reference case, and, in reality, a variety of different sounds can appear in living rooms. It was therefore our ambition to perform a comparison with a large amount of stimuli representative of daily life sounds.

\section{Methods}

A perceptual comparison of the loudness of 64 recorded everyday sounds transmitted through two different walls was made: through (1) a light-weight wall and through (2) a heavy-weight wall.

\subsection{Description of the walls}

The two walls were carefully chosen in order to be characterised by a "typical" light-weight and heavyweight sound transmission index, with different (laboratory measured) spectral responses, but the same single value rating $R_{w}+C_{50-5000}=52 \mathrm{~dB}$. In our experiment, the light-weight wall had higher $\mathrm{R}$ values than the heavy-weight wall in the frequency range between $100-3150 \mathrm{~Hz}$. Below $100 \mathrm{~Hz}$ and above $3150 \mathrm{~Hz}$, the heavy-weight wall was better from the sound insulation point of view.

The light-weight gypsum board wall, with a total thickness of $125 \mathrm{~mm}$, consisted of two $12.5 \mathrm{~mm}$ gypsum board plates with surface density $m^{4}=17.7 \mathrm{~kg} / \mathrm{m}^{2}$ (each plate), $60 \mathrm{~mm}$ of mineral wool, with $m^{\prime}=1.04 \mathrm{~kg} / \mathrm{m}^{2}$ between $75 \mathrm{~mm} \mathrm{C}$ studs, and of two $12,5 \mathrm{~mm}$ gypsum board plates with $m^{*}=17.7$ $\mathrm{kg} / \mathrm{m}^{2}$ each and represents a mass-springmass system. The masonry wall (lime sand brick) had a basic thickness of $175 \mathrm{~mm}$, with $\mathrm{m}^{\prime}$ around $305 \mathrm{~kg} / \mathrm{m}^{2}$ and was plastered on one side. The laboratory measured sound transmission spectra of the two walls, are given in Figure 1. 


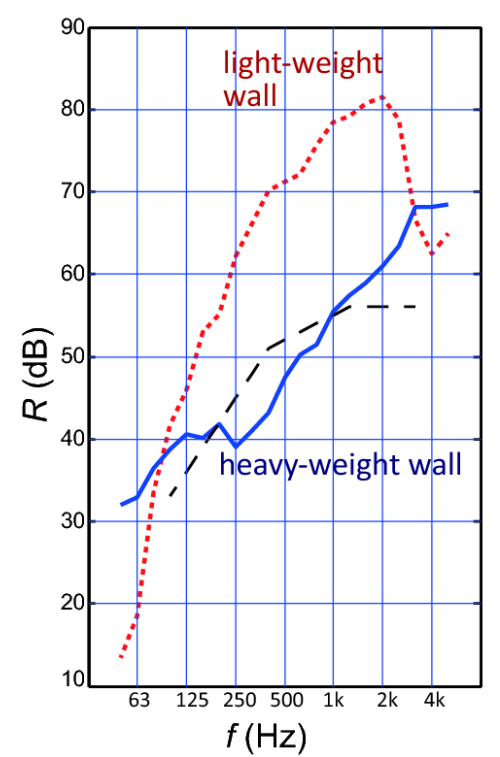

Figure 1. Sound reduction index $\mathrm{R}(\mathrm{dB})$ as measured in the laboratory.

The single number quantities (SNQ) $R_{\mathrm{w}}+C_{100-3150,} R_{\mathrm{w}}+C_{100-5000,} R_{\mathrm{w}}+C_{50-3150}$ and $R_{\mathrm{w}}+C_{50-5000}$ reached values of $52 \mathrm{~dB}$ in the case of the heavy-weight wall. In the case of the light-weight wall these values were $R_{\mathrm{w}}+C_{100-3150}=67 \mathrm{~dB}, R_{\mathrm{w}}+C_{100-5000}=65 \mathrm{~dB}, R_{\mathrm{w}}+C_{50-3150}=52 \mathrm{~dB}$, and $R_{\mathrm{w}}+C_{50-5000}$ $=52 \mathrm{~dB}$.

\subsection{Listening stimuli}

In order to be able to screen a contemporary living noise spectrum in dwellings of multi-storey buildings, recordings were carried out in 10 selected households for a period of up to two weeks during an average busy period of the year [29]. The residents were asked to take part in this preliminary study by giving permission to take sound recordings in their dwellings, with the aim to allow us to evaluate the living noise spectrum in contemporary households. The residents who were asked to take part in the study roughly represented a social average of urban citizens. We succeeded to motivate residents of dwellings located in Vienna and Lower Austria to support the study with their participation. A wide range of living noiserelevant sound events of the recordings were classified and analysed afterwards: conversations between inhabitants while having coffee with guests, watching television, listening to music (radio, via pc, hifi-appliances of a wide range of technical quality, TV, wind-up gramophone), watching home cinema, practicing a musical instrument (piano, flute), playing musical instruments with friends, a small choir practicing songs, vividly playing children, carnival party with children, party, preparing food in the kitchen, using a meat tenderizer and food processor, grinding coffee, operating a dish washer, cleaning up the flat using a vacuum cleaner, operating a washing machine and a spin dryer, gas burner of a gas heating system, brushing teeth with an electric toothbrush, taking a shower, using a hairdryer, barking dogs, domestic dispute. Approximately $51 \%$ of the recorded sounds consisted of music presented via hifi-devices (with a substantial bass content).

All 64 different recorded sounds were filtered by the measured transmission spectra of the two walls, analysed in terms of their A-weighted sound pressure level (expressed in $\mathrm{dB}$ ) and Loudness (expressed in son), and later compared with listening test results.

In Figures 2-4, examples of three stimuli are shown for illustration purposes.

An example of a music fragment, which contains substantial modulation in time at low frequencies, is shown in Figure 2. In this case, both A-weighted sound pressure level Lp and Loudness N indicate that sound transmitted through the light-weight wall should sound louder as the peaks in both parameters are higher for the light-weight wall. The second example (Figure 3) shows the analysis of a music fragment with a substantial degree of broadband time modulation in sound signals, and indicates that sound transmitted through heavy-weight wall should normally be perceived as louder. The example in Figure 4 is a fragment from a movie where the main sound is caused by a crashing airplane. This stimulus was recorded when played through a hifi-system with bass enhancement. 

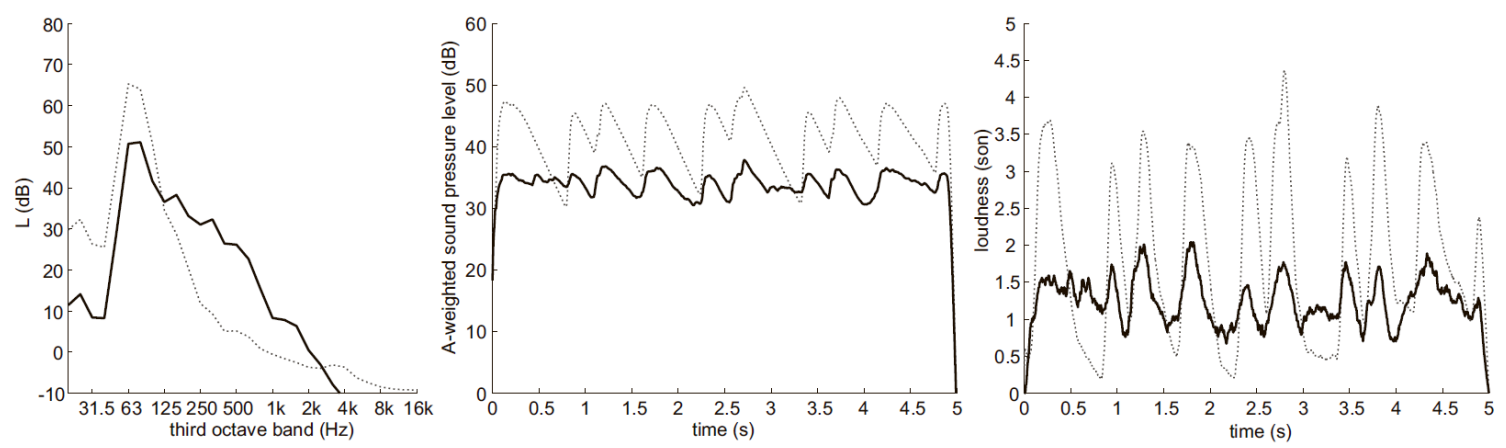

Figure 2. Analysis of a piece of music with strong amplitude variations at low frequencies, after transmission through a light-weight (thin dashed line) and masonry wall (thick full line). Left: overall spectrum of the sound pressure level. Middle: temporal structure of the A-weighted filtered sound pressure level $L_{p}(\mathrm{dBA})$. Right: Loudness N (son).
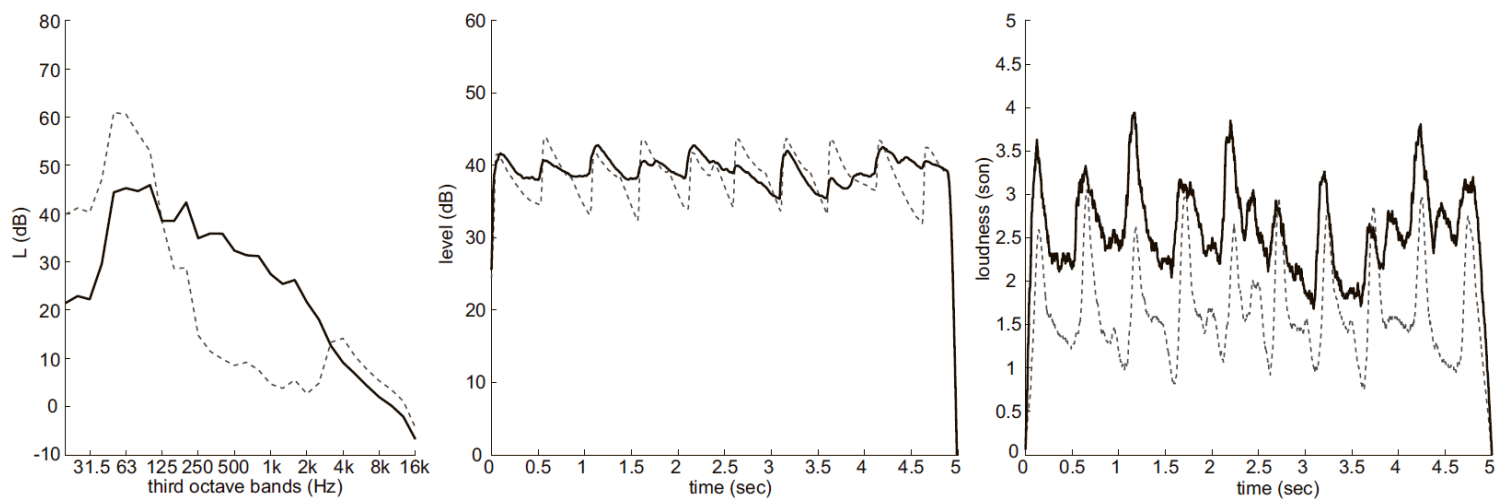

Figure 3. Analysis of a hard rock music (AC DC) fragment with a strong repetitive amplitude modulation after transmission through a light-weight (thin dashed line) and masonry wall (thick full line). Left: overall spectrum of the sound pressure level. Middle: temporal structure of the A-weighted filtered sound pressure level $L_{p}(\mathrm{dBA})$. Right: Loudness N (son).
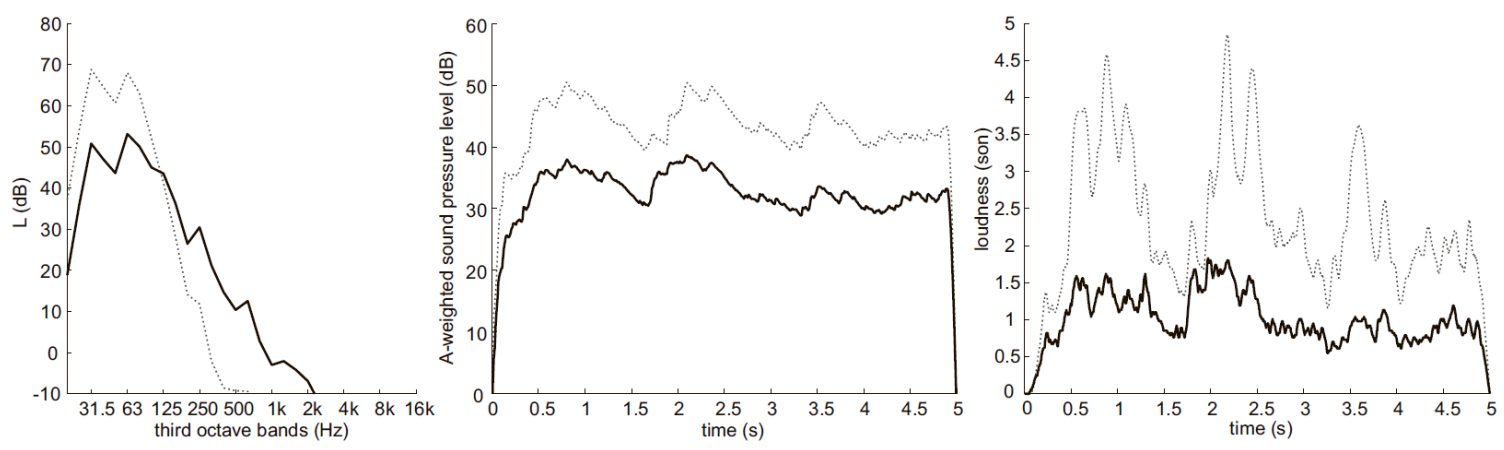

Figure 4. Analysis of a fragment from a movie involving a crashing airplane, played through a hifi-system with bass enhancement, after transmission through a light-weight (thin dashed line) and masonry wall (thick full line). Left: overall spectrum of the sound pressure level. Middle: temporal structure of the A-weighted filtered sound pressure level $L_{p}(\mathrm{dBA})$. Right: Loudness N (son).

\subsection{Listening test protocol}

In psychoacoustics, the forced choice task approach is one of the most powerful methods, as it minimizes the influence of the possible subjects' response uncertainties [35, 36]. In order to discriminate within the presented sound examples, a two-alternative forced-choice task (2AFC) was applied.

The average duration of one test was about 50 minutes. Subjects were allowed to take breaks, or even to stop to test anytime, but none of them actually did. 
Shortly after the listening test, each subject was asked to give his/her feedback on the hearing experience and to give an impression about the test. We did not make use of a questionnaire or a list of prepared questions. Instead, feedback of the subjects was awaited, in an approach similar to grounded theory [40], giving subjects the freedom to highlight the impressions and thoughts about the test, which they judged worth to mention. Answers were analysed and common comments were collected and counted.

Grounded theory is one of the methods typically used in qualitative research in social sciences. An interview typically starts with an open question (which was in our case "How did you like the test? Was it difficult?"). In a later stage, the researcher analyses the interviews and reviews the data according to the repeated opinions or ideas [41]. Grounded theory is often used in preliminary studies to define new research topics or categories and sometimes becomes the basis for a new theory.

\subsection{Subjects}

In total, thirty-nine (39) subjects $\left(\mathrm{N}_{+}=14\right.$ and $\left.\mathrm{N} \hat{\delta}=25\right)$ participated on a first series of perception experiments (Test 1). Thirty-five (35) of them were normal hearing male and female listening subjects (20-45 years old), one woman was sixty-five (65) years old (without reported severe hearing loss), and 3 persons were wearing hearing aids. $50 \%$ of the subjects were between 21 and 25 years old.

\section{Listening experiments}

\subsection{Test 1}

The stimuli were presented to the subject via the headphones of a listening unit (Head Acoustics system) and played on an exact absolute sound level. The sound level in the headphones was calibrated by using an artificial ear device.

During each perception test, each subject was seated alone in an anechoic room in order to avoid background noise or distraction from other subjects. The subject could choose to listen to the stimuli and input his or her answer via a computer screen and mouse. Subjects were allowed to communicate with an operator seated in a next room, for help with technical issues if required.

The questions were presented in a random order (using a homemade Matlab routine), and each pair of sounds was played twice: once first via the light-weight wall $(A)$ and then via the heavy-weight wall $(B)$, and once first via the heavy-weight wall $(B)$ and then via the light-weight wall $(A)$. The $A-B$ and $B-A$ combinations were also played in a random order. The subjects were not informed about the stimuli, i.e. they were not told that they were comparing two walls. They were simply asked to listen carefully to the two sounds and to indicate which sound was perceived "louder", by clicking the respective button in the user interface in a window of the computer screen. The explanation was given in the anechoic room, in order to give each person some time to accommodate to the silent and anechoic environment.

The feedback from subjects supported the results of the test, e.g. listening subjects who reported hearing problems could not hear the most silent stimuli. The most common comment (from 31 out of 39 subjects) of tested subjects was that if they had been asked to decide which sound was "more disturbing" instead of which one "was louder", they would sometimes have answered differently.

\subsection{Test 2}

An additional experiment, with 12 randomly chosen normal hearing subjects was included, in order to confirm or reject the hypothesis that A-weighting of sound pressure level is not an adequate weighting when hearing neighbours' noise (e.g. evaluating sound insulation), due to too low (often $<40 \mathrm{~dB}$ ) sound levels (A-weighting is based on the 40-phon Fletcher-Munson equal-loudness contour and sounds [39] that corresponds to $40 \mathrm{~dB}$ at $1 \mathrm{kHz}$ ).

Based on the overview of all answers in Test 1, in Test 2, all stimuli for which subjects had been hesitating in Test 1, i.e. for which at least one person had indicated the heavyweight wall as the better sound insulator, were chosen. In addition, compared to the first test, the level of those stimuli was equally amplified with $30 \mathrm{~dB}$ over all frequencies. Doing so, most of the sound samples were played at levels around $50-70 \mathrm{~dB}$ LAeq. 
For the sake of shortening the test duration, a further reduction of the number of stimuli was done.

\section{Results and analysis}

\subsection{Test 1}

The results of Test 1 are summarized in Figure 5 as the percentage $p(\%)$ for which a sound transmitted through the light-weight construction was heard louder than the one transmitted through the heavy-weight wall. Although the value of $R_{\mathrm{w}}+C_{50-5000}$ of the two walls was the same, i.e. $52 \mathrm{~dB}$, most of the normal hearing subjects perceived the sound transmitted through the heavy-weight wall as louder (Figure 5). Only in the case of the movie reproduction including the noise of a crashing airplane and reproduced via a hifi-system with bass enhancement, $34 \%$ of normal hearing subjects assigned the sound transmitted from the light-weight wall as louder.

\subsection{Test 2}

The results from Test 2, in which the overall level in the headphones was increased with $30 \mathrm{~dB}$, are shown in Figure 6. Although the results are based on a statistically small sample of subjects, the trend is very clear.

Interestingly, during the feedback interview, several subjects (including those whose answer was still consistent with a heavy-weight wall having the weakest insulation) were spontaneously commenting to the researcher running the second test as follows: ". . . you have put the bass sound louder than in the previous test. . .". Nine subjects mentioned that the test was more difficult now and eight of them spontaneously commented, that if their task would have been to chose a more "disturbing sound" instead of "louder" sound, they often would have answered differently. All eight subjects described the rhythmic bass and drum sound in music stimuli as disturbing.

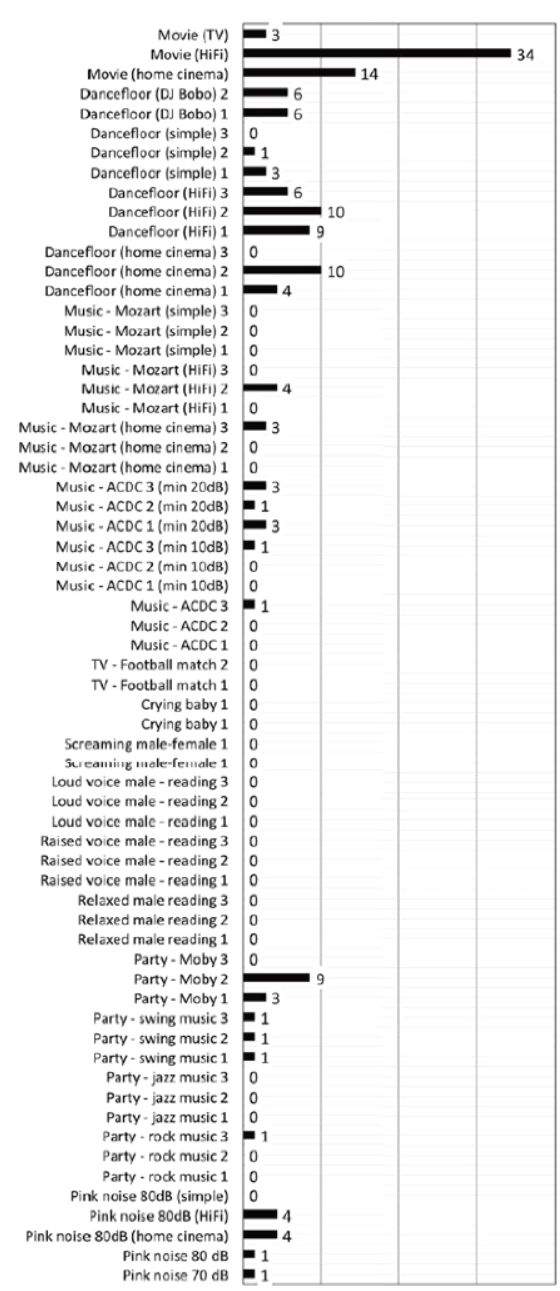

Figure 5. Percentage of answers among subjects with normal hearing for which a sound transmitted through lightweight construction was heard louder than the one from a heavy-weight wall. 


\section{Discussion}

\subsection{Test 1}

Only a few times subjects' suggested that the light-weight construction was a weaker sound insulator. This occurred in cases where music or a film was amplified by the neighbours' home cinema or by powerful hifi-system with large amounts of deep bass sound. The light-weight wall had a significantly better perceived performance in the range $100-3150 \mathrm{~Hz}$ in comparison with the heavy-weight wall. The behaviour at frequencies lower than $100 \mathrm{~Hz}$ explains why these two walls have the same $R_{w}+C_{50-5000}$ value and indicate an overestimation of these frequencies in weighting. Findings in the study of Hongisto [21] regarding a music stimulus with traffic noise spectrum of ISO 717-1 confirm our result, since in that study the $R_{w}+C_{50-5000}$ rating for the mentioned stimulus with strong bass sound was among the best 4 investigated single number quantity (SNQ) predictors $\left(R_{\mathrm{w}}+C_{100-3150,} R_{\mathrm{w}}+\right.$ $C_{100-5000,} R_{w}+C_{50-3150}$ and $R_{w}+C_{50-5000)}$ of loudness. Interestingly, in the field study of the AkuLite project different findings were reported for impact sounds [42].

Although the amount of subjects (39) did not allow us to perform a detailed statistical analysis, we can see a few trends that can serve as an indicator for future research. One pronounced influencing factor is the age of the subject, connected with the occurrence of hearing loss at higher frequencies. Seniors and people with hearing impairment that participated in our experiment probably heard middle and high frequencies less loud and therefore, in comparison with normal hearing people, they possibly perceived the bass sounds as relatively louder (hence corresponding with giving preference to the heavy-weight wall as being the better sound insulator). Although for listening tests that are meant for validation of acoustic quantities, people with normal hearing are recommended, practically speaking, building acoustic standards should fulfill the requirements of the majority of dwelling users. The question arises if the standards should be always based on sound perception of young healthy people, which were reported in [43] to complain less about neighbours' noise than the elderly.

\subsection{Test 2}

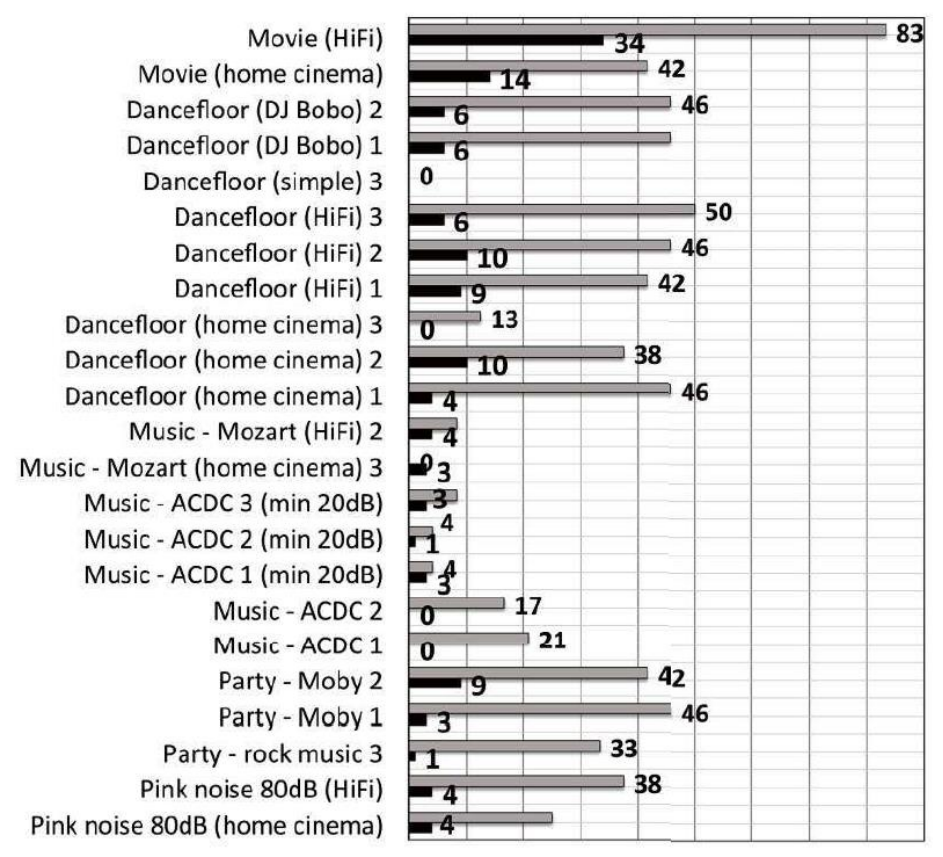

Figure 6. Percentage of answers where stimuli transmitted through light-weight construction were heard louder than those heard through a heavy-weight wall. The results of the Test 1 in which stimuli were played on a realistic sound level are plotted in black colour, while the results of the Test 2, where stimuli were presented $30 \mathrm{~dB}$ louder are shown in grey.

Objective answers from perception tests (Figure 6), together with the verbal feedback of the subjects, qualitatively confirm the trend given by equal loudness contours, i.e. low frequencies are perceived less loud at low intensities than at higher sound intensities. This implies that, although the equal loudness contours are based on experiments with pure tones [33], they can also be used as a basis for understanding of perception of loudness of more complex sounds. 
Moreover, the importance of presenting sound stimuli on a realistic absolute level for sound insulation assessment studies [22] was confirmed. This also indicates that the low background noise levels in the listening room are crucial for the correct outcome of the perception tests and that the results of tests conducted under non-calibrated conditions have poor reliability.

Finally, the spontaneous feedback of eight subjects opens new questions in terms of "noise disturbance". The majority of studies done with respect to the perception of sound insulation considered only spectral information of stimuli [11, 19, 21, 24, 26, 27], also in cases when not only loudness but also disturbance or annoyance was addressed. Nevertheless, the temporal aspects of neighbours' noise should be also addressed in future studies, as people are very sensitive to temporal amplitude modulations [44]. It would also be interesting to investigate masking effects from background noise in the listeners' room, which can be expected to be present in real life situations.

\section{Conclusion}

The performed listening test experiments indicate that the single number quantity $R_{w}+C_{50-5000}$ does not represent the loudness perception of "living noise" transmitted through partitions. Although the single value rating for two chosen walls was the same, listening tests performed with 35 normal hearing subjects show an overestimation of the importance of low frequencies in the proposed single number quantity $R_{\mathrm{w}}+C_{50-5000}$ for sounds at low intensities, such as typical noise coming from neighbours. The results show that, only when playing transmitted sounds unrealistically loud, the adequacy of the above mentioned single value rating could become a better indicator of airborne sound insulation.

Listening tests show that the light-weight wall scores better for most of the assessed living noise

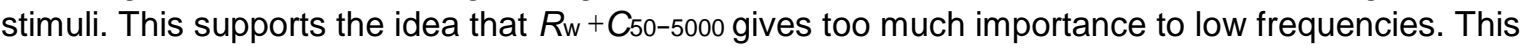
overestimation results from accumulated errors in the spoken SNQ $\left(R_{w}+C_{50-5000}\right)$ method, i.e. (i) exaggeration of low frequency content in the approximation of "living noise" by "pink noise", and (ii) the invalid presumption that A-weighting can be adequately applied in the assessment of complex sounds at low intensities, such as neighbour's noise.

Although our results are based only on one SNQ $\left(R_{w}+C_{50-5000)}\right)$ they are consistent with the ones in references [21, 32]. Mortensen et al. [11] had different findings, which can be explained by their use of very high sound pressure levels (110 dBA), which are typical for situations of e.g. very loud party music levels, but not for the majority of daily life sounds. Research to investigate the adequacy of alternative single-value ratings is ongoing.

\section{References}

[1] ISO Recommendation R 717:1968: Rating of sound insulation for dwellings.

[2] ISO 717-1:1982: Acoustics - Rating of sound insulation in buildings and of building elements - Part 1: Airborne sound insulation in buildings and of interior building elements.

[3] ISO 717-1:1996: Acoustics - Rating of sound insulation in buildings and of building elements - Part 1: Airborne sound insulation.

[4] ISO 717-1:1996 + AM1:2006: Acoustics - Rating of sound insulation in buildings and of building elements Part 1: Airborne sound insulation.

[5] ISO 717-1:2013: Acoustics - Rating of sound insulation in buildings and of building elements - Part 1: Airborne sound insulation.

[6] E. Shove: Comfort, cleanliness and convenience: the social organization of normality. Oxford, 2003.

[7] J. Mathys: Low-frequency noise and acoustical standards. Applied Acoustics 40 (1993) 185-199.

[8] J. H. Rindel: Acoustic quality and sound insulation between dwellings. Journal of Building Acoustics 5 (1999) $291-301$.

[9] B. Rasmussen: Sound classification of dwellings - Quality class ranges and intervals in national schemes in Europe. Proceedings Euronoise, Prague, Czech Republic, 2012.

[10] e-book Building acoustics throughout Europe: Volume 1: Towards a common framework in building acoustics throughout Europe. e-ISBN: 978-84-697-0158-4. Editors: Maria Machimbarena and Birgit Rasmussen. Publication supported by COST. Vibration 346 (2015) 100-116.

[14] N. B. Roozen, L. Labelle, M. Rychtáriková, C. Glorieux: Determining radiated sound power of building structures by means of Laser Doppler Vibrometry. Journal of Sound and Vibration 346 (2015) 81-99.

[15] V. Hongisto: Sound insulation of double panels-comparison of existing prediction models. Acta Acustica united with Acustica 92 (2006) 61-78.

[16] A. Dijckmans, G. Vermeir: A wave based model to predict the niche effect on sound transmission loss of single and double walls. Acta Acustica united with Acustica 98 (2012) 111-119. 
[17] C. Hopkins: Experimental statistical energy analysis of coupled plates with wave conversion at the junction. Journal of Sound and Vibration 322 (2009) 155-166.

[18] M. Lievens, C. Höller, P. Dietrich, M. Vorländer: Predicting the interaction between structure-borne sound sources and receiver structures from independently measured quantities: Case study of a washing machine on a wooden joist floor. Acta Acustica united with Acustica 100 (2014) 79-92.

[19] H. K. Park, J. S. Bradley: Evaluating standard airborne sound insulation measures in terms of annoyance, loudness, and audibility ratings. The Journal of the Acoustical Society of America 126 (2009) 208-219.

[20] M. Vorländer, R. Thaden: Auralisation of airborne sound insulation in building. Acta Acustica united with Acustica 86 (2000) 70-76.

[21] V. Hongisto, D. Oliva, J. Keränen: Subjective and objective rating of airborne sound insulation-living sounds. Acta Acustica united with Acustica 100 (2014) 848-863.

[22] M. Horvat, K. Jambrošić, H. Domitrović: Examination of required signal-to-noise margin in laboratory subjective evaluation of sound insulation. Proceedings of AAAA 2012, Petrčane, Croatia, 2012.

[23] M. Horvat, K. Jambrošić, H. Domitrović: Suitability of 3D sound reproduction and the influence of background noise on subjective assessment of sound insulation. Proceedings of the Euronoise 2012, Prague, Czech Republic, 2012.

[24] T. H. Pedersen, S. Antunes, B. Rasmussen: Online listening tests on sound insulation of walls - A feasibility study. Proceedings of Euronoise 2012.

[25] M. Rychtáriková, H. Muellner, M. Stani, V. Chmelík, C. Glorieux: Does the living noise spectrum adaptation of sound insulation match the subjective perception? Proceedings of the Euronoise 2012, Prague, Czech Republic, 2012.

[26] R. O. nez, C. Visentin, M. Marković, P. Fausti: Objective and subjective evaluation of façade sound insulation. Proceedings of Internoise 2013, Innsbruck, Austria, 15-18 September 2013.

[27] S. Bailhache, J. Jagla, C. Guigou-Carter: CSTB - Projet environnement et ambiances: effet des basses frequences sur le confort acoustique - tests psychoacoustiques. Report CSTB 2014 https://hal.archivesouvertes.fr/hal-01045056/document.

[28] B. Rasmussen, J. H. Rindel: Sound insulation between dwellings - Descriptors applied in building regulations in Europe. Applied Acoustics 71 (2010) 171-180.

[29] H. Muellner, M. Rychtáriková: Empirical evaluation of the contemporary living noise spectrum in multi-family houses - a preliminary study. Proceedings of Internoise 2013, Innsbruck, Austria, 2013.

[30] M. Vorländer: Auralization. Fundamentals of acoustics, modelling, simulation, algorithms and acoustic virtual reality. RWTH edition, Springer Verlag, 2008.

[31] ISO/TS 15666:2003: Acoustics - Assessment of noise annoyance by means of social and socio-acoustic surveys.

[32] V. Hongisto, M. Suokas, M. Mäkilä: Satisfaction with sound insulation in residential dwellings - the effect of wall construction. Building and Environment 85 (2015) 309- 320.

[33] ISO 226:2013: Acoustics - Normal equal-loudness-level contours.

[34] Y. Suzuki, H. Takeshima: Equal-loudness-level contours for pure tones. Journal of the Acoustical Society of America 116 (2004) 918-933.

[35] D. M. Green, D. McFadden: Psychological acoustics. - In: Encyclopedia of Acoustics, Volume III. M. J. Crocker (ed.). John Wiley \& Sons, Inc, New York, 1997.

[36] E. Zwicker, H. Fastl: Psychoacoustics - Facts and models, 2nd edition. Springer-Verlag, Berlin Heidelberg New York, 1999.

[37] J. Chalupper, H. Fastl: Dynamic loudness model (DLM) for normal and hearing-impaired listeners. Acta Acustica united with Acustica 88 (2002) 378-386.

[38] G. Grimm, V. Hohmann, J. L. Verhey: Loudness of fluctuating sounds. Acta Acustica united with Acustica 88 (2002) 359-368.

[39] P. Susini, S. McAdams, B. K. Smith: Loudness asymmetries for tones with increasing and decreasing levels using continuous and global ratings. Acta Acustica united with Acustica 93 (2007) 623-631.

[40] B. G. Glaser, A. L. Strauss: The discovery of grounded theory: Strategies for qualitative research. Transaction Publishers, 1967.

[41] M. Domecka, M. Eichsteller, S. Karakusheva, P. Musella, L. O. E. Perone, D. Pickard, A. SchröderWildhagen, K. Siilak, K. Waniek: Method in practice: Autobiographical narrative interviews. - In: Search of European Phenomena in "The Evolution of European Identities: Biographical Approaches". R. Miller, G. Day (eds.). Palgrave Macmillan, 2012, 21-44.

[42] P. Thorsson: Laboratory listening tests on footfall sounds: Akulite report 7. Report 2013:5, Department of Civil and Environmental Engineering, Chalmers University of Technology, ISSN 1652-9162, 2013.

[43] A. Vargova, M. Rychtarikova: Typical complaints of inhabitants in Slovakian dwellings and constructional defects related to sound insulation. European Symposium Harmonization of European Sound Insulation Descriptors and Classification Standards, Florence, December 14th, 2010.

[44] B. De Coensel, D. Botteldooren, T. De Muer, B. Berglund, M. E. Nilsson, P. Lercher: A model for the perception of environmental sound based on notice-events. Journal of the Acoustical Society of America 126 (2009) 656-65. 